\title{
A Novel dual Band Hexagonal Antenna for Bluetooth and UWB Applications With Single Band Notched
}

\author{
Mourad Elhabchi ${ }^{1}$, Mohamed Nabil Srifi ${ }^{2}$, Raja Touahni $^{1}$ \\ ${ }^{1}$ LASTID Laboratory, Department of physics, Faculty of Sciences, Ibn Tofail University ,Kenitra, Morroco \\ ${ }^{2}$ Electronics and Telecommunication Systems Research Group, National School of Applied Science (ENSA), Ibn Tofail \\ University, kenitra,morroco \\ *corresponding author, E-mail: mouradelhabchi@hotmail.fr
}

\begin{abstract}
This paper presents a modified hexagonal regular broadband antenna operating from $(3.3 \mathrm{GHz}-10.5 \mathrm{GHz})$ with integrated Bluetooth band and single band notched.The Bluetooth band is integrated in ultrawideband (UWB) structure when the antenna is loaded by a pair of inverted $\square$-shaped strips.To avoid interference with the UWB systems, the wireless local area network(WLAN) of $5.72-5.825 \mathrm{GHz}$ is notched by incorporating a complementary split ring resonator (SRR) slot within the hexagonal shaped . The operating frequencies ranges of the proposed antenna are $2.22 \mathrm{GHz}-2.52 \mathrm{GHz}$ and 3.5 $\mathrm{GHz}-10 \mathrm{GHz}$, which covers, Bluetooth $(2.4 \mathrm{GHz}-2.484$ $\mathrm{GHz})$ and UWB $(3.1 \mathrm{GHz}-10.6 \mathrm{GHz})$ band, except the range of WIAN $(5.72 \mathrm{GHz}-5.825 \mathrm{GHz})$ with return loss more than $10 \mathrm{~dB}$. The performance of the antenna is simulated and optimized by CST Microwave Studio and validated against using Ansoft HFSS . The surface current distribution is used to analyze the effects of the slot and strips. The antenna gain is acceptable over both Bluetooth and UWB bands. In the band notched regions, the gain reduces from its normal value about $4 \mathrm{dBi}$ at $5.75 \mathrm{GHz}$.
\end{abstract}

\section{Introduction}

In recent years, UWB systems become very attractive since the Federal Communications Commission (FCC) released the frequency band from $3.1 \mathrm{GHz}$ to $10.6 \mathrm{GHz}$ to be an unlicenced band with a good effective radiated power spectral density of $-41.3 \mathrm{dBm} / \mathrm{MHz}$ [1]. Printed monopole antennas fabricated on a substrate offer wide impedance bandwidth that can cover UWB behavior.The several monopole antenna has been studied such as Rectangular [2], circular disc [3], elliptical [4], and hexagonal UWB monopole antennas [5-6]. Besides UWB and Bluetooth are some applications that take advantage of license-free frequency of operation in the Industrial, Scientific, and Medical (ISM) band covering the $2.40-2.484-\mathrm{GHz}$ band. To integrate these bands for use in one device, it 's essential to develop a dual band [7-8]. Most research focusing on UWB and Bluetooth integrated antenna have been reported in [910]. However, over the frequency range of UWB, there are other narrowband wireless communication systems with can interfere with the broadband elements, such as wireless local area network (WLAN), operating in the range of $5.72 \mathrm{GHz}$ $5.825 \mathrm{GHz}$. Therefore, in order to avoid interference with the other bands a filter-antenna should be designed to reject such undesirable bands. Inserting the split ring resonators (SRRs) or complementary split ring resonators (CSSRs) in the hexagonal antenna, is a new way to achieve a band notched characteristics. Several scientific paper's use of split-ring resonators (SRRs) and complementary split-ring resonators (CSRRs) to design band-notched UWB antennas have been presented in [11]. Various approaches have been observed in the literature [12] in order to achieve single and dual band notches such as U-Shaped Slot and W-Shaped Slot [13], C-Shaped Slots [14] elliptical slot uwb antenna with half circular ring radiator element [15].The band stop frequency can be controlled by adjusting the length or radius of the hexagonal design. In this paper, we propose a hexagonal dual-band antenna for Bluetooth and UWB applications with the WIAN stop band. The reference hexagonal design resonates in the Ultra-Wideband (UWB) from 3.3 to $10.5 \mathrm{GHz}$. By loading a pair of Inverted $\Gamma$ Shaped strip on the top edge of the radiating element, the Bluetooth band $(2.4 \mathrm{GHz}-2.484 \mathrm{GHz})$ is integrated into the conventional UWB hexagonal structure. The WLAN (5.72 GHz-5.825 GHz) band is filtered by slotting a complementary split ring resonator (SRR) into the radiating hexagonal shaped. This letter contributes towards obtaining tri-band antenna with wide bandwidth without increasing their size and also to design simple-structured, low profile, omnidirectional structure with an acceptable gain.

\section{Antenna Design}

The details of the proposed hexagonal shaped are depicted in Fig. 1. The antenna is printed on a layer of dielectric substrate (ROGERS $4350 \mathrm{~B}$ ) with permittivity of $\varepsilon_{\mathrm{r}}=3.66$ , loss tangent of $\tan \delta=0.004$ and height of $\mathrm{h}=0.51 \mathrm{~mm}$. The dimensions of the substrate are $31 \times 40 \mathrm{~mm}^{2}$. The width of the feed line is fixed at $\mathrm{wf}=1.08 \mathrm{~mm}$ to achieve $50 \Omega$ impedance matching.

The lower band edge frequency has been determined for UWB using [16-17] :

$$
\mathrm{f}_{\mathrm{l}}=\frac{\mathrm{c}}{\lambda}=\frac{72}{(\mathrm{H}+\mathrm{R}+\mathrm{p}) \times \mathrm{k}^{\prime}}
$$


Where $\mathrm{H}$ is the height of the printed hexagonal structure, $\mathrm{R}$ is the effective radius of the equivalent cylindrical monopole antenna.

$\mathrm{p}=\mathrm{Lf}-\mathrm{Lg}$, the length of the gap between the upper edge and the lower edge of the ground plane of the radiation element, and the factor $\mathrm{k}^{\prime}=1.15$ is the value for the effect of dielectric material type.With the reference to the proposed radiating hexagonal element shown in Figure-1-a, the parameters above can be obtained as follows:

$\mathrm{H}=\sqrt{3} \mathrm{R}$

$r=\frac{3 R}{4 \pi}$

By giving $\mathrm{R}$ the value of $11.6 \mathrm{~mm}$, parameters of $\mathrm{H}$ and $\mathrm{r}$ can be calculated by precedent Equations. We can determine The value of $p=0.5 \mathrm{~mm}$ by Equation- 1 .
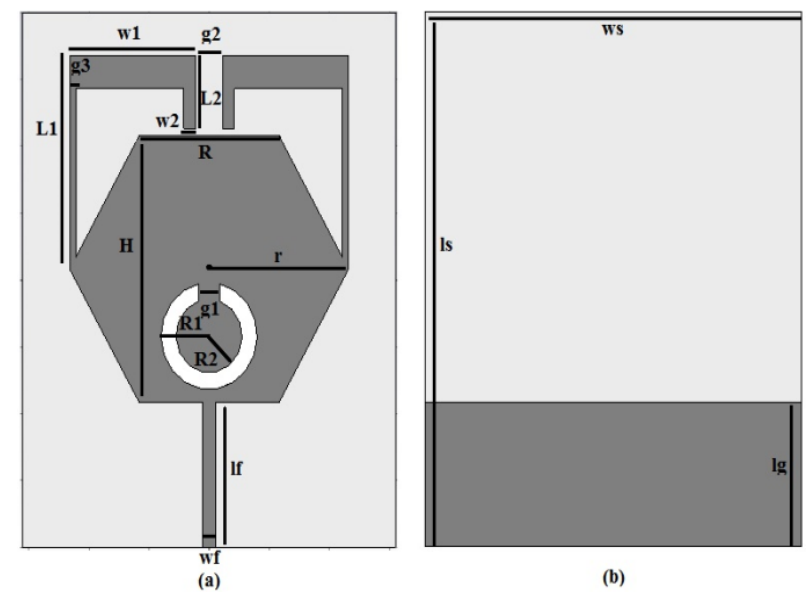

Figure 1: This is the figure Geometry of proposed antenna (a) top view, (b) Bottom view.

\subsection{Bluetooth Band Integrated in UWB Antenna}

A pair of $\Gamma$-Shaped strip Inverted with a length of $\mathrm{w}_{1}+$ $\mathrm{L}_{1}+\mathrm{L}_{2}$, and width of $\mathrm{W}_{2}$ are loaded on the top edge of the proposed design .Hence, the Bluetooth band $(2.4 \mathrm{GHz}-$ $2.484 \mathrm{GHz}$ ) is integrated into UWB antenna (fig. 2.Ant II). The antenna generates dual-band frequencies due to two different resonating elements. The length $L_{B}$ of the inverted -Shaped is etched to be about a quarter wavelength for the central Bluetooth band resonant [18].

$\mathrm{L}_{\mathrm{B}}=\frac{\mathrm{c}}{4 \mathrm{f}_{\mathrm{B}}}$

$\mathrm{L}_{\mathrm{B}}=\mathrm{L}_{1}+\mathrm{L}_{2}+\mathrm{w}_{1}$

\subsection{Band Notched Antenna Design}

In order to obtain a notch band in the frequency range of 5.72-5.825 GHz, a single complementary split ring resonators CSRR is etched in the radiation patch as shown in (fig. 2.Ant III). The characteristics of SRRs and CSRRs have been studied in [19-20]. Usually, the length of the slot is made approximately equal to half the guided wavelength at the notch frequency of the band [21].

$$
\begin{aligned}
& \mathrm{L}_{\text {Total-wlan }}=\frac{\lambda_{\mathrm{g}}}{2}=\frac{\mathrm{c}}{2 \mathrm{f}_{\text {notch-wlan }} \sqrt{\frac{\varepsilon_{\mathrm{r}+1}}{2}}} \\
& \mathrm{~L}_{\text {Total-wlan }}=2 \pi\left(\mathrm{R}_{1}+\frac{\mathrm{Ws} 1}{2}\right) \frac{\theta}{360}
\end{aligned}
$$

Where $\mathrm{L}_{\text {total_wLAN }}$ is the total length of the slot. For the notch frequency $\mathrm{f}_{\text {notch } \text { WLAN }}=5.75 \mathrm{GHz}$, the outer Radius of the slot R1 is calculated as $4 \mathrm{~mm}$. The slot width is found to be $\mathrm{R} 1-\mathrm{R} 2=1.25 \mathrm{~mm}$. by a way of CST and HFSS simulations in order to find the exact filter band.

The dimensions of the radiating regular hexagonal antenna without CSRR slot and inverted $\Gamma$-shaped are listed in Table.1 below. Fig. 2. shows the evolution stages of the proposed design.

Table 1: Dimension of regular hexagonal antenna

\begin{tabular}{lllll}
\hline symbole & ws & ls & wg & lg \\
Dimensions $(\mathrm{mm})$ & 31 & 40 & 31 & 10 \\
\hline symbole & Lf & $\mathrm{H}$ & $\mathrm{r}$ & wf \\
Dimensions $(\mathrm{mm})$ & 10.8 & 20 & 10 & 1.08 \\
\hline
\end{tabular}

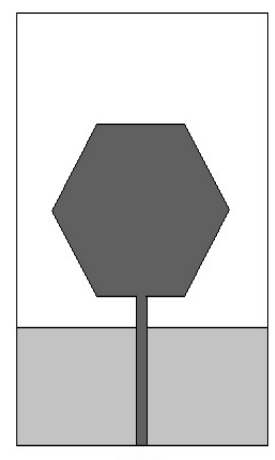

Ant I

(the prototype antenna)

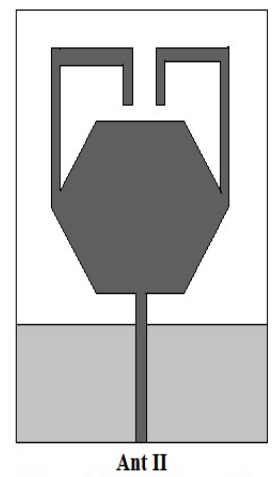

the prototype antenna with inverted $\Gamma$-shaped

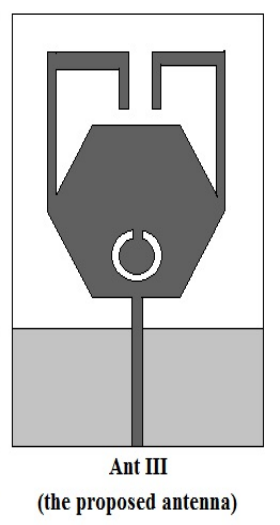

(the proposed antenna)
Figure 2: The structures of the prototype and proposed antennas.

\section{Results and Discussion}

The simulated return loss of impedance matching for proposed integrated Bluetooth in UWB hexagonal antenna with a single W1AN notched band as depicted in Figure-1, was shown as case (III) of fig. 3.

For the antenna denoted as Ant I, it's the reference prototype and has resonates in the Ultra-Wideband from 3.3 to 10.5 GHz. As the top side of the antenna loaded by a pair of Shaped (Ant II), the Bluetooth band is integrated into UWB antenna with good impedance matching (Trace II).

To stop WLAN band (Ant III).The hexagonal shaped is incorporated by a complementary split ring resonator (CSRR) slot (Trace III).

It is clearly observed that the proposed design cannot change the property of ulta-wideband feature with added a pair of $\Gamma$ shaped strip and complementary split ring resonator (CSRR) slot. 


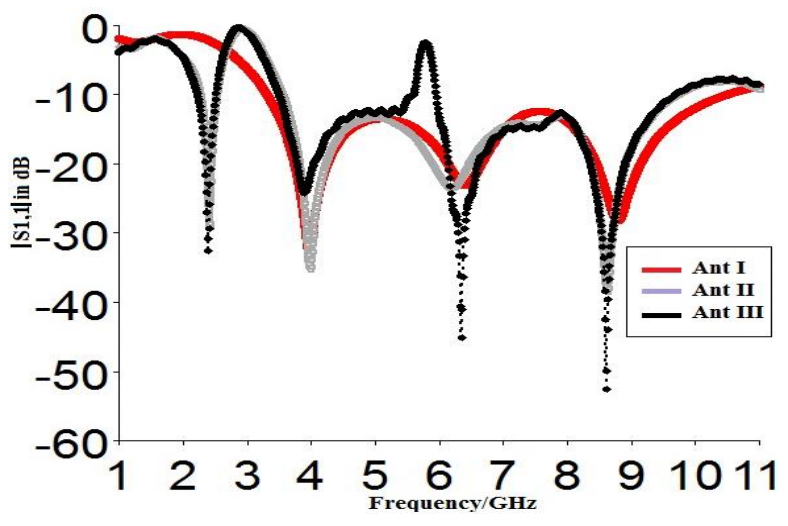

Figure 3: Simulated $S_{11}$ parameters of the proposed antenna with different structures.

\subsection{Parametric Study and Observation}

A parametric study is carried out to investigate the effects of the important parameters on the impedance matching as shown in Fig. 1. Witch represents the configuration of the proposed antenna.

In order to study the influence of the $\Gamma$-shaped on the UWB structure, we analyze the performance of them by tuning the parameters $\mathrm{L}_{1}, \mathrm{~W}_{1}, \mathrm{~L}_{2}, \mathrm{~W}_{2}$ and $\mathrm{g}_{3}$ using CST Microwave Studio. Coefficient reflexion characteristics for various parameters of loaded inverted $\Gamma$-shaped are simulated and shown in fig. 4.5.6.7 and fig. 8.

The effect of the length $L_{1}$ is presented in Fig. 4. With the increase of this length from $17 \mathrm{~mm}$ to $20 \mathrm{~mm}$, the lower edge frequency of the response moves toward the left side of the plot. The width $\mathrm{W}_{1}$ effect on the input impedance is shown in Figure 5. From the results, it's observed that the width W1 plays a significant role for impedance matching when its value increased from $4 \mathrm{~mm}$ to $10 \mathrm{~mm}$ resulting good frequency resonant. Fig. 6. depict the simulation results of $\mathrm{S}_{11}$ with different values of $\mathrm{L}_{2}$, this figure indicate that a center frequency move towards the right side of the plot with decreasing of $\mathrm{L}_{2}$ from $4 \mathrm{~mm}$ to $1 \mathrm{~mm}$.

In Fig.7. The effect of changing the width $\mathrm{W}_{2}$ on $\mathrm{S}_{11}$ parameters is shown, with a fixed value of the other parameters. To see this effect, the width $\mathrm{W}_{2}$ of $\Gamma$-shaped was tuned gradually from $1 \mathrm{~mm}$ to $7 \mathrm{~mm}$ by a step of $2 \mathrm{~mm}$. Its effect is clearly observed that can move the Bluetooth band toward lowest frequency with a slight decrease in bandwidth and return loss.

The effect of $\mathrm{g}_{3}$ and its optimization is presented in Fig. 8 . As the width $\mathrm{g}_{3}$ increases from $0.3 \mathrm{~mm}$ to $0.9 \mathrm{~mm}$, the center resonant frequency shifts towards higher frequency.

From the above discussion, it can be concluded that the Bluetooth band can be controlled by varying the strips dimensions. The optimal values of $\Gamma$-shaped for good impedance matching are listed in the table.2.

Table 2: Optimal parameters values of $\Gamma$-shaped.

\begin{tabular}{cccccc}
\hline symbole & L1 & W1 & L2 & W2 & g3 \\
\hline Dimensions $(\mathrm{mm})$ & 17 & 10 & 3 & 1 & 5 \\
\hline
\end{tabular}

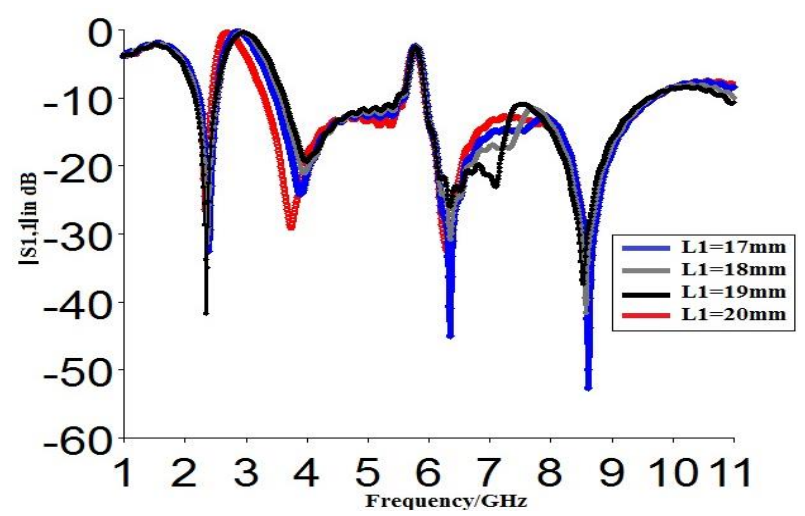

Figure 4: Simulated reflection coefficient for different $\mathrm{L}_{1}$

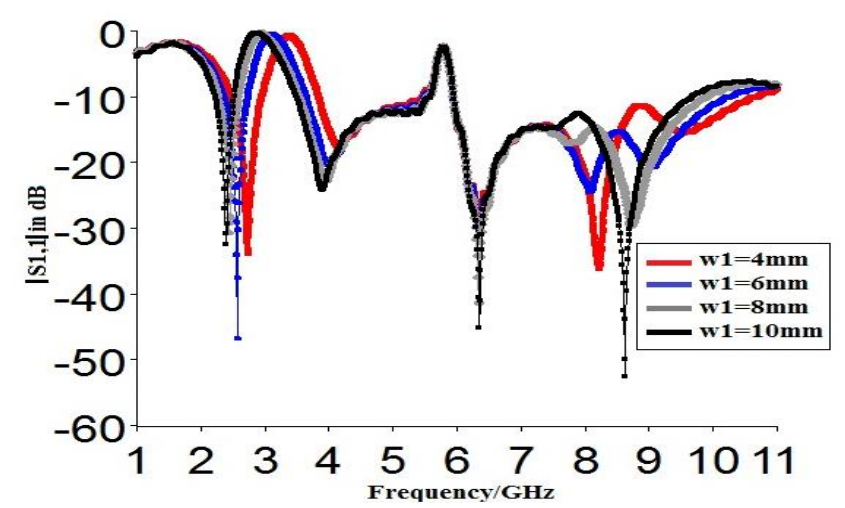

Figure 5: Simulated reflection coefficient for different $\mathrm{W}_{1}$

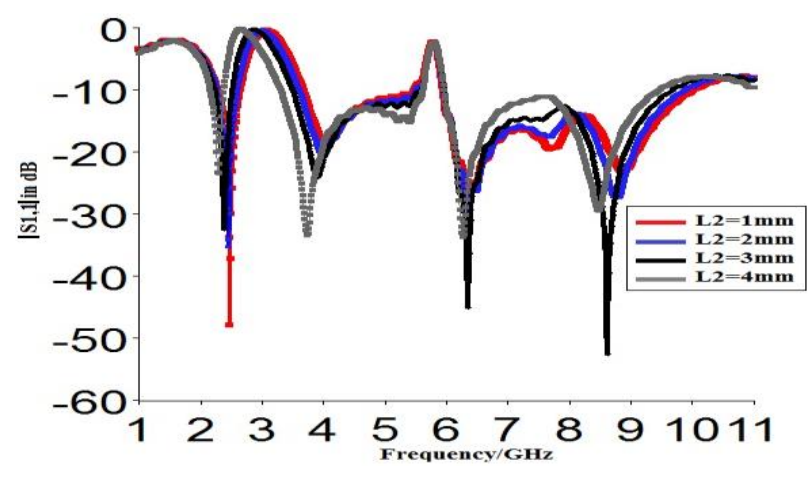

Figure 6: Simulated reflection coefficient for different $L_{2}$

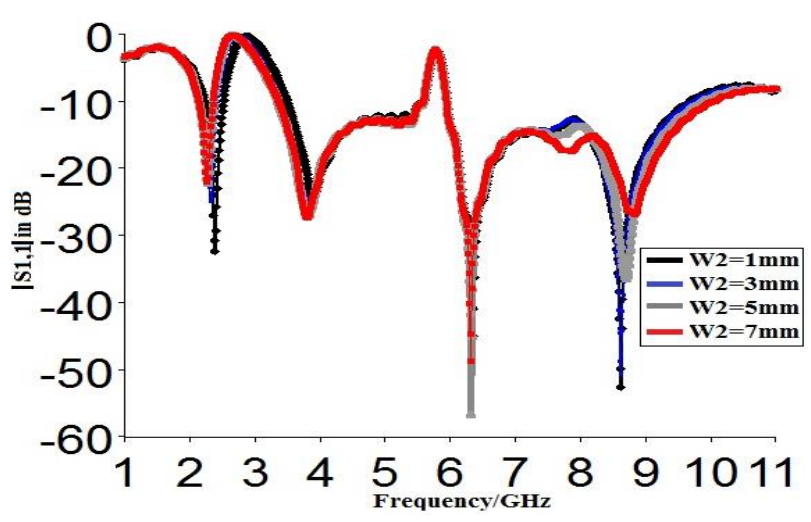

Figure 7: Simulated reflection coefficient for different $\mathrm{W}_{2}$ 


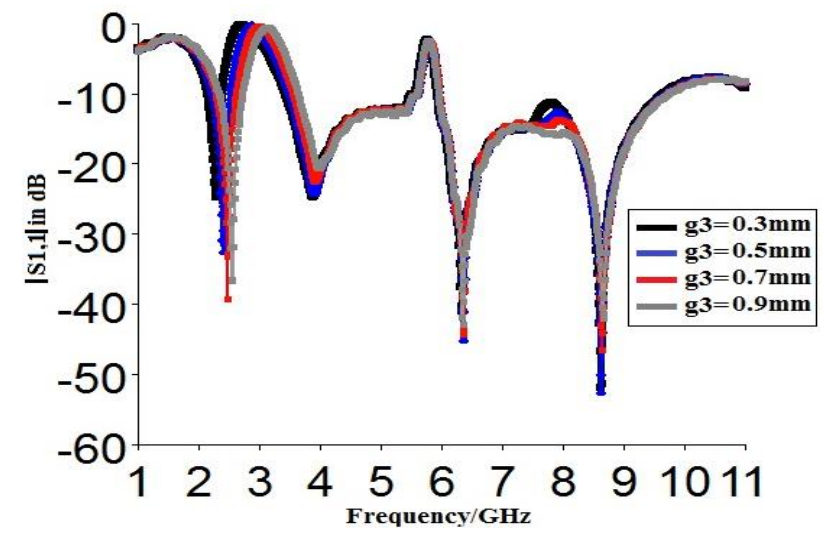

Figure 8: Simulated reflection coefficient for different $g_{3}$

\subsection{Notch Band Parameters Effects}

The band notch is created by etching a complementary split ring slot (CSRR) in the hexagonal radiating element. In the CSRR, the central frequency of notch band can be approximately calculated by Equations-6-7.

Fig. 9. Shows the simulated reflexion coefficient results of different outer complementary split ring slot radius R1 with fixed values of other parameters, the central frequency of the WLAN notched band is obviously changed towards lowest frequency while the outer radius $\mathrm{R}_{1}$ is increased from $2.5 \mathrm{~mm}$ to $3.25 \mathrm{~mm}$. In fig. 10 . it is observed that the central frequency $\mathrm{f}_{\text {-notched-Wlan }}$ is changed with different values of inner complementary split ring radius $R_{2}$ slot while increasing from $3 \mathrm{~mm}$ to $4.5 \mathrm{~mm}$ by a step of $0.5 \mathrm{~mm}$, the other bands are slightly changed of parameter $R_{2}$ due to the coupling between antenna parameters. From Fig. 11. The central frequency $\mathrm{f}_{\text {-notched-WLAN }}$ band moves leftwards with increasing the gap g1 from $0.5 \mathrm{~mm}$ to $2 \mathrm{~mm}$. Furthermore, the central frequencies notched WLAN band can be adjusted and controlled by the parameters of the complementary split ring slot. The optimal values of CSRR slot for good impedance matching are listed in the table. 3 .

Table :3 optimal parameters values of Compelementary split ring resonator.

\begin{tabular}{cccc}
\multicolumn{5}{c}{ ring resonator. } \\
\hline symbole & $\mathrm{R}_{1}$ & $\mathrm{R}_{2}$ & $\mathrm{~g}_{1}$ \\
\hline Dimensions $(\mathrm{mm})$ & 4 & 1.75 & 2 \\
\hline
\end{tabular}

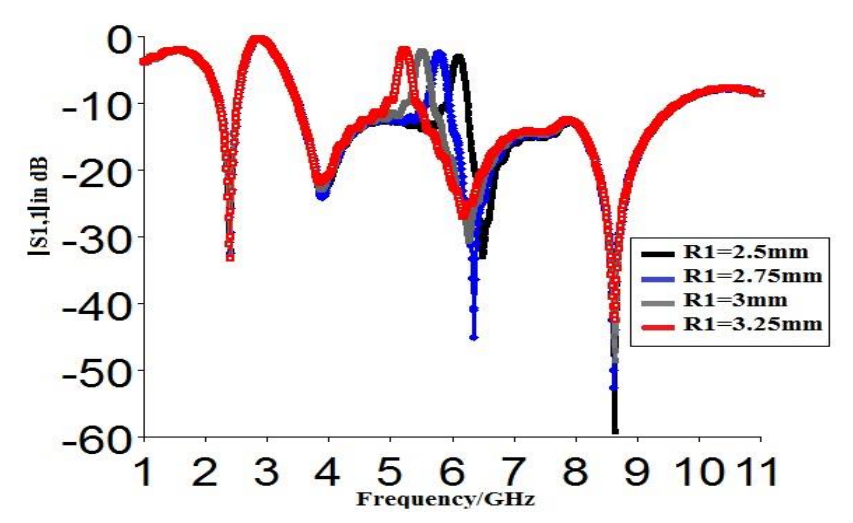

Figure 9: Simulated reflection coefficient for different $\mathrm{R}_{1}$

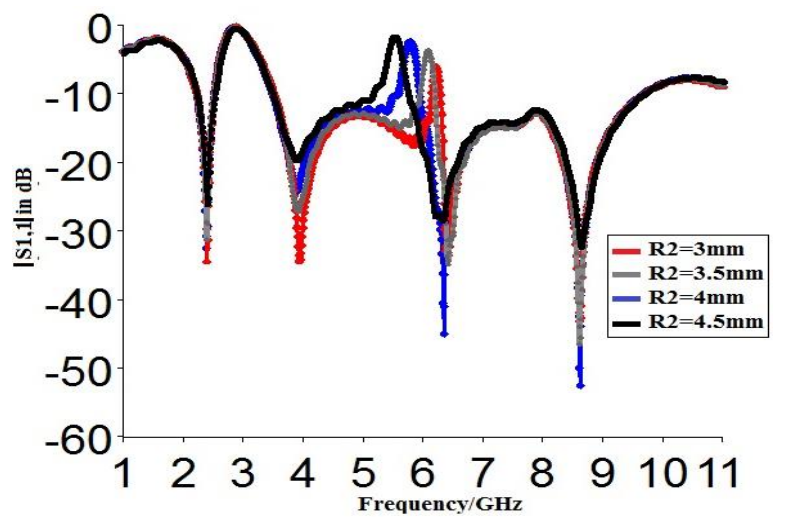

Figure 10: Simulated reflection coefficient for different $R_{2}$

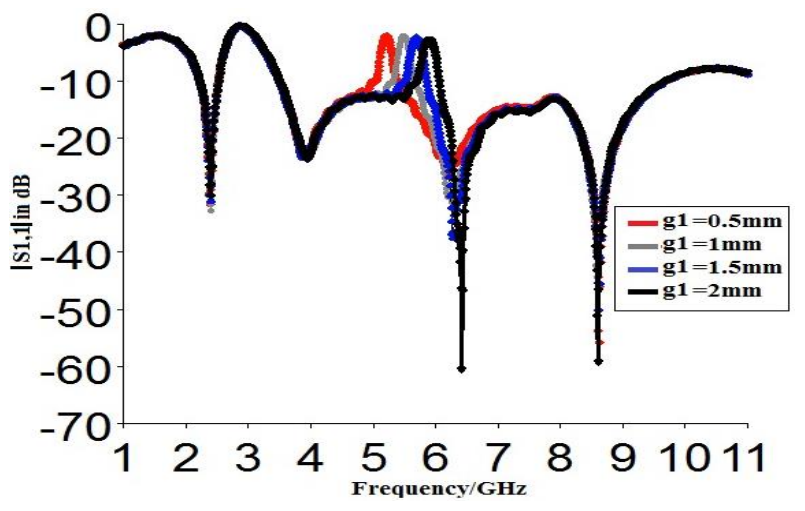

Figure 11: Simulated reflection coefficient for different $g_{1}$

\subsection{Current Distributions and Gain Results}

The current distributions give us the idea of the proposed antenna behavior.Fig.12.depicts it's density at $2.4 \mathrm{GHz}$ and $5.75 \mathrm{GHz}$, The current is significantly high in $\Gamma$-shaped strip (Fig. 12.a), which denotes that the $\Gamma$-shaped strip resonates at $2.4 \mathrm{GHz}$. Fig. 12.b shows that the current density is very high in the Complementary split ring resonator (CSRR) at $5.75 \mathrm{GHz}$, while relatively very low at $\Gamma$-shaped in this frequency.

The surface current flows around CSRR to reject undesired WLAN band .It clearly shows the important effects of the stubs and the slot in integrating Bluetooth band and achieving the WLAN band-notched properties.

Fig. 13. Shows the 3D plot of the field pattern and the gain value of the proposed antenna at each selected frequency. The results showed in this figure reveal that the proposed integrated Bluetooth hexagonal antenna with notch band provides an acceptable quasi-omnidirectional radiation pattern suitable for receiving signals from all directions. The antenna gain is variable from $2.37 \mathrm{dBi}$ to $5.37 \mathrm{dBi}$ across the desired frequency except the notched band.witch the value of gain is negative (fig. 13.b) bacause at the notch band there is a worse impedance matching(the return loss is More than $-10 \mathrm{dBi})$. 


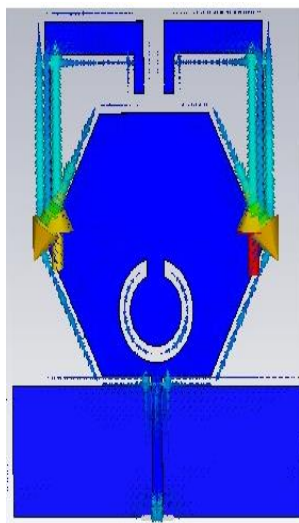

(a)

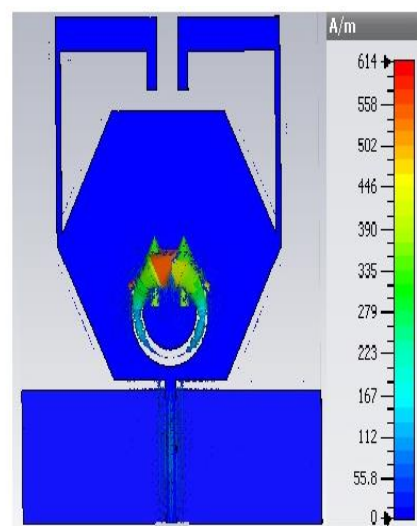

(b)
Figure 12: Simulated current distribution of frequencies at. (a) $2.4 \mathrm{GHz}$, (b) $5.75 \mathrm{GHz}$.

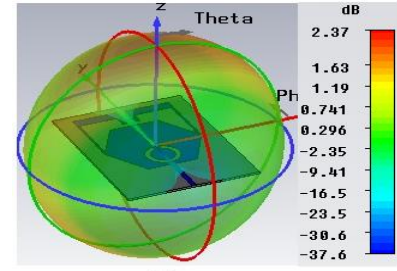

(a)

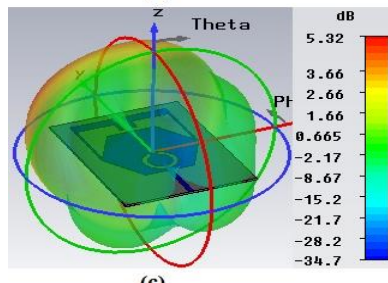

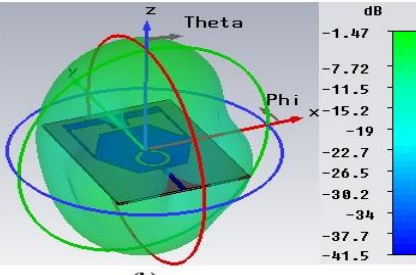

(b)

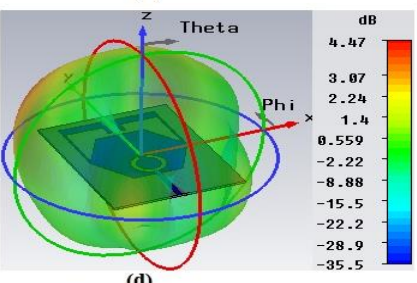

Figure $13: 3 \mathrm{D}$ plot of field pattern shows the gain at : (a) $2.4 \mathrm{GHz}$; (b) $5.75 \mathrm{GHz}$; (c) $7.5 \mathrm{GHz}$; (d) $8.5 \mathrm{GHz}$.

These figures show that integrated Bluetooth band in UWB hexagonal antenna with notch band keep the properties of UWB in the term of gains.

After the use of CST software design. We designed and simulated the proposed hexagonal antenna as HFSS to validate our design. Figure.14 illustrates the return loss obtained by both softwares.

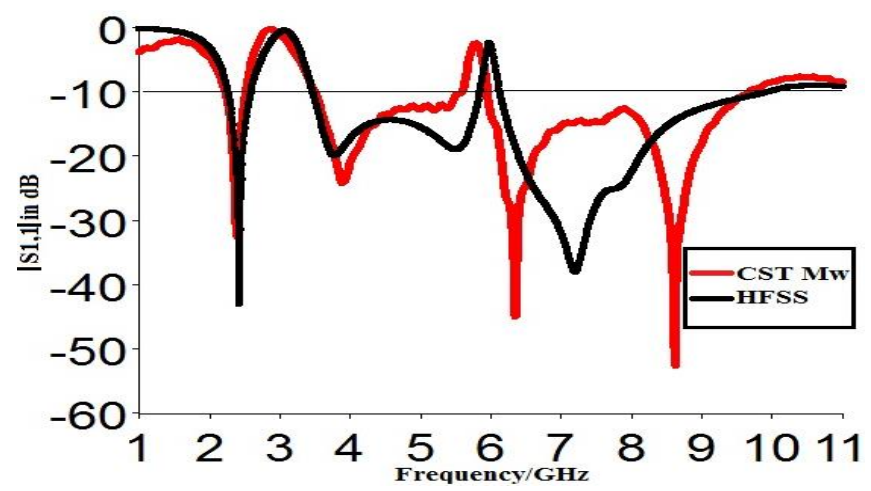

Figure 14: Comparison between the return loss.
We observe a good agreement between the simulated results. There is a slight difference of the resonant frequency, but, the bandwidth simulation results are very comparable.

\section{Comparison Between Recently Developed Research}

Finally, the proposed integrated Bluetooth with WLAN reject band antenna and the other antennas cited in this paper are compared in Table. 4. The structure proposed in this work not only can resonate in the UWB and Bluetooth bands, but also has the advantages of good WLAN band notched ranges and acceptable gain features.

Table 4: Comparison between recently proposed antennas and this antenna.

\begin{tabular}{|c|c|c|c|}
\hline Antennas & $\begin{array}{c}\text { Dimensions } \\
\left(\mathrm{mm}^{3}\right)\end{array}$ & $\begin{array}{c}\text { Operating } \\
\text { Bands }\end{array}$ & $\begin{array}{c}\text { Gain(dB) } \\
\text { (Except } \\
\text { WLAN } \\
\text { Band) }\end{array}$ \\
\hline $\begin{array}{l}\text { This } \\
\text { paper }\end{array}$ & $31 \mathrm{X} 40 \mathrm{X} 0.51$ & $\begin{array}{c}\text { Bluetooth } \\
\text { and UWB } \\
\text { with notch } \\
\text { band }\end{array}$ & $2.37-5.32$ \\
\hline $\operatorname{Ref}[3]$ & $30 \times 35 \times 1.6$ & UWB & $2.5-5.5$ \\
\hline $\operatorname{Ref}[7]$ & $42 X 46 X 1.6$ & $\begin{array}{l}\text { Bluetooth } \\
\text { and UWB }\end{array}$ & $3.5-5.5$ \\
\hline $\operatorname{Ref}[8]$ & $42 X 24 X 1.6$ & $\begin{array}{l}\text { Bluetooth } \\
\text { and UWB }\end{array}$ & $2.5-4.5$ \\
\hline Ref[10] & $36 \times 42 \times 1$ & $\begin{array}{c}\text { Bluetooth } \\
\text { and UWB } \\
\text { with notch } \\
\text { band }\end{array}$ & $2.1-5.5$ \\
\hline $\operatorname{Ref[13]}$ & $35 \times 30 \times 1.6$ & $\begin{array}{l}\text { UWB with } \\
\text { notch band }\end{array}$ & $\begin{array}{c}\text { Not } \\
\text { defined }\end{array}$ \\
\hline Ref[17] & $30 \times 30 X 1.6$ & UWB & $1.75-3.5$ \\
\hline
\end{tabular}

\section{Conclusion}

A compact and planar Bluetooth and UWB hexagonal antenna with single band-notched is presented. On the basis of ultra-wideband, we add Bluetooth function by embedding a pair of $\Gamma$-shaped parasitic strip. Hence, the antenna can operate on both Bluetooth and UWB frequency range for return loss less than $-10 \mathrm{~dB}$.Through performing the radiating element by a complementary split ring resonator (CSRR), a notch band from $5.72 \mathrm{GHz}$ to $5.95 \mathrm{GHz}$ is generated to suppress the interference of WLAN. The simulation results show that the proposed antenna with a compact size, simple structure, good WLAN band-notched characteristics, and wide bandwidth can be a good candidate for UWB application. Therefore, the results of the work are useful for short-range wireless communication systems. 


\section{Acknowledgements}

The authors would like to thank team of the Laboratory of Information System and Telecommunications, AbdelmaleK Essaâdi University for their support to carry out this work.

\section{References}

[1] N. Agrawall, G. Kumar, and K. Ray , "Wide-band planar monopole antennas", IEEE Trans. Antennas Propag, vol. 46, no. 2, pp. 294-295, Feb 1998.

[2] Y. C. Lin and K.J. Hung, "Compact ultra-wide band rectangular aperture antenna and band-notched designs”, IEEE Trans. Antennas Propag, vol. 54, no. 11, pp. 3075-3081, Nov 2006.

[3] M. N. Srifi, S. K. Podilchak, M. Essaaidi, and Y. M. Antar, "Compact Disc Monopole Antennas for Current and Future Ultrawideband (UWB) Applications", IEEE Trans. Antennas Propag, vol. 59, no. 12, pp. 44704480, Dec 2011.

[4] A. S. Elkorany, G. T. Ahmed, D. A. Saleeb, "A Planar UWB Antenna with Dual Band Rejection Capability Using Double Rotated ESRRs", Advanced Electromagnetics, vol. 7, no. 1, pp.19-24, Jan 2018.

[5] T. Mandal and S. Das, "A Coplanar Waveguide Fed Hexagonal Shape UWB Antenna with WiMAX and WLAN Band Rejection", Radioengineering, vol. 23, no. 4, pp. 1077-4485, Dec 2014.

[6] X. Gong, L. Tong, Y. Tian, and B. Gao, "Design of a Microstrip-Fed Hexagonal Shape UWB Antenna with Triple Notched Bands", Progress In Electromagnetics Research C, vol. 62, pp. 77-87, Jan 2016.

[7] B. S. Yildirim, B. A. Cetiner, G. Roqueta, and L. Jofre, "Integrated Bluetooth and UWB antenna", IEEE Antennas and wirless Propag. Lett, vol. 8, pp. 149-152, Jan 2009.

[8] S. K. Mishra, R. K. Gupta, A. Vaidya, and J. Mukherjee, "A Compact Dual-Band Fork-Shaped Monopole Antenna for Bluetooth and UWB Applications", IEEE Antennas and wirless Propag. Lett, vol. 10, pp. 627-630, Jun 2011.

[9] Z. Han, Z. Ma, and Q. Xue, "Integrated Bluetooth and UWB Antenna with Single Band-Notched", Applied computational Electromagnetics Society journal, vol. 30, no. 8, pp. 838-843, Aug 2015.

[10] Y. F. Weng, S. W. Cheung, and T. I. Yuk, “An antenna for UWB and Bluetooth standards with band-notched characteristic", IEEE International Conference on UltraWideband, pp. 170-174, Sep 2009.

[11] Y. Zhang, W. Hong, C. Yu, Z. Q. Kuai, Y. D. Don and J. Y. Zhou, "Planar ultra-wideband antennas with multiple notched bands based on etched slots on the patch and/or split ring resonators on the feed line", IEEE Trans. Antennas Propag. vol. 56, no. 9, pp.30633068, Sep 2008.
[12]P. Kumar and J. L. M. Campos, "Dual Polarized Monopole Patch Antennas for UWB Applications with Elimination of WLAN Signals", Advanced Electromagnetics, vol. 5, no. 1, pp.46-52, May 2016.

[13]M. S. Ahmed, M. R. Islam, and S. Khan, "design of dual band notched uwb antenna using (U-W) shaped slots", ARPN Journal of Engineering and Applied Sciences, vol. 10, no. 23, pp.17375-17379, Dec 2015.

[14] X. L. Liu, Y. Z. Yin, and J. H. Wang, “A compact dual band-notched UWB antenna with meandering slot and C-shape strips", Microw. Opt. Technol. Lett”, vol. 55, no. 11, pp. 2631-2636, Aug 2013.

[15] A. Elboushi, O. M. Ahmed, and A. R. Sebak , " study of elliptical slot uwb antennas with A 5.0-6.0 GHz band-notch capability", Progress In Electromagnetics Research C, vol. 16, pp.207-222, Oct 2010.

[16]K. P. Ray, "Design aspects of printed monopole antennas for ultra-wide band applications", International Journal of Antennas and Propagation. Article ID 713858, 8 pages, Jan 2008.

[17] A. A. M. Shaalan and M. I. Ramadan, "Design of a compact hexagonal monopole antenna for ultrawideband applications", J. InfraredMilli Terahz Waves ,vol. 31, pp.958-968, Mai 2010.

[18] S. K. Mishra, R. K. Gupta, A.Vaidya, and J. Mukherjee, "Printed Fork Shaped Dual Band Monopole Antenna for Bluetooth and uwb applications with $5.5 \mathrm{GHz}$ Wlan Band Notched Characteristics " Progress In Electromagnetics Research C, vol. 22, pp.195-210, Jui 2011.

[19] G. Monti and L. Tarricone, "Negative Groupe Velocity in a Split ring Resonator-Coupled Microstrip Line", Progress In Electromagnetics Research, vol 94 , pp. 3347, 2009.

[20] A. S. Al-Zayed, M. A. Al-Bagli, and V. A. Shameena, "Design and Analysis of a Band-Notched Staircase Ultra-Wide band Antenna," Progress In Electromagnetics Research C, vol. 75, pp.121-130, 2017.

[21] G. P. Gao, Z. L. Mei, and B. N. Li, "Novel Circular Slot Uwb Antenna With Dual Band-Notched characteristic", Progress In Electromagnetics Research C, vol. 15, pp.49-63, 2010. 